\title{
GIS Database and Google Map of the Population at Risk of Cholangiocarcinoma in Mueang Yang District, Nakhon Ratchasima Province of Thailand
}

\author{
Soraya J Kaewpitoon', Ratana Rujirakul², Apinya Joosiri², Sirinun Jantakate², \\ Amnat Sangkudloa ${ }^{3}$, Sarochinee Kaewthani ${ }^{4}$, Kanokporn Chimplee ${ }^{5}$, Kritsakorn \\ Khemplila $^{6}$, Natthawut Kaewpitoon ${ }^{7}$
}

\begin{abstract}
Cholangiocarcinoma (CCA) is a serious problem in Thailand, particularly in the northeastern and northern regions. Database of population at risk are need required for monitoring, surveillance, home health care, and home visit. Therefore, this study aimed to develop a geographic information system (GIS) database and Google map of the population at risk of CCA in Mueang Yang district, Nakhon Ratchasima province, northeastern Thailand during June to October 2015. Populations at risk were screened using the Korat CCA verbal screening test (KCVST). Software included Microsoft Excel, ArcGIS, and Google Maps. The secondary data included the point of villages, sub-district boundaries, district boundaries, point of hospital in Mueang Yang district, used for created the spatial databese. The populations at risk for CCA and opisthorchiasis were used to create an arttribute database. Data were tranfered to WGS84 UTM ZONE 48. After the conversion, all of the data were imported into Google Earth using online web pages www.earthpoint.us. Some 222 from a 4,800 population at risk for CCA constituted a high risk group. Geo-visual display available at following www.google.com/maps/d/u/0/ edit?mid=zPxtcHv_iDLo.kvPpxl5mAs90\&hl=th. Geo-visual display 5 layers including: layer 1, village location and number of the population at risk for CCA; layer 2, sub-district health promotion hospital in Mueang Yang district and number of opisthorchiasis; layer 3, sub-district district and the number of population at risk for CCA; layer 4, district hospital and the number of population at risk for CCA and number of opisthorchiasis; and layer 5, district and the number of population at risk for CCA and number of opisthorchiasis. This GIS database and Google map production process is suitable for further monitoring, surveillance, and home health care for CCA sufferers.
\end{abstract}

Keywords: GIS - google map - population at risk - cholangiocarcinoma - Thailand

Asian Pac J Cancer Prev, 17 (3), 1293-1297

\section{Introduction}

Cholangiocarcinoma (CCA) is a serious problem in Thailand particularly in northeastern and northern region. Database of population at risk are need required for monitoring, surveillance, home health care, and home visit. Therefore, this study aimed to develop the geographic information system (GIS) database and Google map of the population at risk for CCA in Mueang Yang district, Nakhon Ratchasima province, northeastern Thailand during June to October 2015. Populations at risk for CCA, were screened by using Korat CCA verbal screening test (KCVST). Software were included Microsoft excel,
ArcGIS, and Google Maps. The secondary data included the point of villages, sub-district boundaries, district boundaries, point of hospital in Mueang Yang district, used for created the spatial databese. The populations at risk for CCA, opisthorchiasis, and CCA, used for created the arttribute database. Data were tranfered to WGS84 UTM ZONE 48. After the conversion, all of the data were imported into Google Earth using online web pages www. earthpoint.us. Of 222 from 4,800 populations at risk for CCA, was a highrisk group and 2 patients infected with $\mathrm{O}$. viverrini and 2 abnormal bile duct. Geo-visual display available at following www.google.com/maps/d/u/0/ edit?mid=zPxtcHv_iDLo.kvPpxl5mAs90\&hl=th. Geo-

${ }^{1}$ School of Family Medicine and Community Medicine, ${ }^{2}$ Parasitic Disease Research Unit, ${ }^{7}$ Suranaree University of Technology Hospital, Suranaree University of Technology, ${ }^{4}$ Social Development Program, Faculty of Humanities and Social Science, ${ }^{5}$ GeoInformatics Program, Faculty of Science and Technology, ${ }^{6}$ Environmental Technology Program, Nakhon Ratchasima Rajabhat University, , Nakhon Ratchasima, ${ }^{3}$ Information Technology Program, Faculty of Information Technology, Maha Sarakham Rajabhat University, Maha Sarakham, Thailand *For correspondence: Natthawut Kaewpitoon 
visual display 5 layers included layer 1 ; village location and number of population at risk for CCA, layer 2; subdistrict health promotion hospital in Mueang Yang district and number of opisthorchiasis, layer 3; sub-district district and the number of population at risk for CCA, layer 4; district hospital and the number of population at risk for CCA and number of opisthorchiasis, and layer 5; district and the number of population at risk for CCA and number of opisthorchiasis. These GIS database and Google map production process is suitable for the use in the further monitoring, surveillance, and home health care for CCA.

Keyword; GIS, Google map, Population at Risk, Cholangiocarcinoma, Thailand

\section{Introduction}

Cholangiocarcinoma (CCA) is a major health problem in Thailand particularly in the northeastern and northern regions. It is also known to be one of the most common causes of cancer related to death in Thailand and it has been reported that Thailand is the highest incident of the world (Green et al., 1991; Sripa et al., 2007; Shin et al., 2010). . It has an annual incidence rate of 1-2 cases per 100,000 in the Western world, but rates of CCA have been rising worldwide over the past several decades (Landis et al., 1998; Patel, 2002). CCA is a neoplasm that involves the epithelial cells of the bile duct. CCA is originated in the bile duct in which drained bile from the liver into the small intestine. This disease is difficult to have early diagnosis, as most symptoms present late in the disease course. In addition, the specific anatomic position can cause periductal extension and result in a very low radical excision rate and a very poor prognosis. Furthermore, CCA is considered to be an incurable and rapidly lethal disease unless all the tumors can be fully resected. Three-year survival rates of $35 \%$ to $50 \%$ are achieved only in a subset of patients who have negative histological margins at the time of surgery (Akamatsu et al., 2011). Survival of CCA patients in northeastern Thailand after supportive treatment was reported and indicated that the stage of disease was an important prognosis factor affecting survival of CCA patients who had diagnosis in late stage. To e encourage patients to see health personnel at early stage is very important (Thunyaharn et al., 2013). Palliative therapeutic approaches, consisting of percutaneous and endoscopic biliary drainage, have usually been used for these patients because there is no effective chemotherapeutic treatment for this type of cancer.

The high mortality rate of CCA was reported in the northeast areas where found frequently of Opisthorchis viverrini infection (Sripa et al., 2010). Recently, O. viverrini has been classified as Type 1 carcinogens by the International Agency for Research on Cancer, World Health Organization (WHO) (IARC, 1994). Mortality rate of liver cancer and $\mathrm{O}$. viverrini infection rate in different regions of Thailand has been reported and found that Nakhon Ratchasima province has 13.67-16.2 per 100,000 populations. In addition, the distribution O. viverrini infection in Nakahon Ratchasima province has been reported, the prevalence of survey in 2009 was $4.6 \%$ (Sitthithaworn et al., 2012). A total of 1,168 stool samples were obtained from 516 males and 652 females. Stool examination showed that $2.48 \%$ were infected with $\mathrm{O}$. viverrini (Kaewpitoon et al., 2012c). Furthermore, a total of 640 Cyprinidae family fish including 5 species were collected from different study sites of Nakhon Ratchasima province, and investigated for $\mathrm{O}$. viverrini metacercariae. The infection rate was $12.3 \%$ (79/640), predominantly in Cyclocheilichthys armatus, C. repasson, Puntioplites proctzysron, Hampala macrolepitota and Hampala dispar, respectively. The prevalence of $\mathrm{O}$. viverrini metaceria was found covered $78.1 \%$ of areas, predominantly in Sida and KiaKham Thale So (Kaewpitoon et al., 2012a). Therefore, using GIS and Google map are conducted in Meuang Yang district, Nakhon Ratchasima province, northeastern Thailand, between June and October 2015. This data is useful for further monitoring, surveillance, and home visit the population at risk.

\section{Materials and Methods}

\section{Study location}

The study was conducted in Meuang Yang district, Nakhon Ratchasima province, northeastern Thailand, between June and October 2015. The study protocol was approved by Suranaree University Ethical Review Committee, EC58-48. Meuang Yang is a district in the northeastern part of Nakhon Ratchasima province. This district is coverage areas 255.06 kilometer2 (98.6 sq mi), located at latitude $15^{\circ} 21^{\prime} 34.61$ " - $15^{\circ} 31^{\prime} 29.92$ " N and longitude $102^{\circ} 46^{\prime} 13.27^{\prime \prime}-103^{\circ} 0$ ' $48.80^{\prime \prime} \mathrm{E}$. The district is subdivided into 4 sub-districts, including Mueang Yang, Krabueang Nok, Lahan Pla Khao, and Non Udom subdistrict, and 44 villages. This district is coverage areas $255.5 \mathrm{~km} 2$. Neighboring districts are (from the north clockwise) Ban Mai Chaiyapot, Phutthaisong and Kho Mueang of Buriram province, Lam Thamenchai, Chum Phuang and Prathai of Nakhon Ratchasima Province.

\section{Study population}

Populations at risk for CCA, were screened by using Korat CCA verbal screening test (KCVST) which contained the history with (1) opisthorchiasis (2) undercooked fish consumption, (3) praziquantel used (4) cholangitis or cholecystitis, (5) relative family with CCA (6) naïve northeastern people, (7) agriculture, and (8) alcohol consumption. Population at risk was identified following $1+2+3+4+5+6+7+8$, who had a score with more than 5 points was selected.

\section{Software, data collection and management}

Software were used in this study, including Microsoft excel; created the descriptive database, ArcGIS; created the database of geographic information system, analysis the spatial and descriptive data, and KML data, and Google Maps; used for geo-visual display online. Spatial and Attribute databases were used for GIS Database. The secondary data included the point of villages, subdistrict boundaries, district boundaries, point of hospital in Mueang Yang district, used for created the spatial databese. While, target populations were populations at risk for CCA; screened by using Korat CCA verbal screening test, opisthorchiasis were examined by using 
GIS Database and Google Map of the Population at Risk of Cholangiocarcinoma in Mueang Yang District, Nakhon Ratchasima Table 1. Population at risk of liver fluke and cholangiocarcinoma using Korat CCA verbal screening, classified by catchment areas of health service

\begin{tabular}{ccccc}
\hline Sub-district & Hospital & Code & Number areas & Population at risk \\
\hline Mueang Yang & Mueang Yang hospital & 11602 & 4 & 615 \\
Mueang Yang & Health promotion hospital of Lin Fa & 2855 & 7 & 875 \\
Krabueang Nok & Health Promotion Hospital of Krabueng Nok & 2856 & 12 & 1,295 \\
Lahan Pla Khao & Health Promotion Hospital of Khon Buri & 2857 & 11 & 1,253 \\
Non Udom & Health Promotion Hospital of Mueang Jak & 2858 & 10 & 762 \\
\hline
\end{tabular}

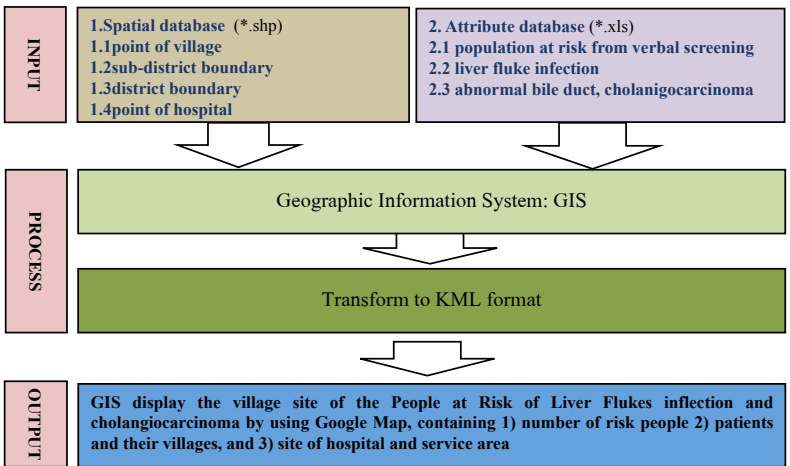

Figure 1. Diagrammatic of utilized geographic information system and google map for monitoring and surveillance the population at risk of cholangiocarcinoma in Mueang Yang district, Nakhon Ratchasima province, Thailand

stool examinantion, and CCA were dianosis using by ultrasonography, used for created the arttribute database. Data management were collected the spatial database and then tranfered to WGS84 UTM ZONE 48. Village point, where had the populations at risk for CCA, opisthorchiasis, abnormal bile duct, and CCA, were used to analyze and calculate with ArcGIS 9.2. After the conversion, all of the data were imported into Google Earth (GE) using online web pages www.earthpoint.us. This web pages using HTML codes (village point was a primary key) to export the coordinate to. $\mathrm{kml}$ format that can be recognized by GE (Figure 1,2). Nowadays, the data can be viewed in GE, Figure 3 indicating all of the case locations are spread on the map.

\section{Results}

A total of 4,800 population at risk for CCA was screened from 10,580 people by using Korat CCA verbal screening test. The majorities were habitated in Mueang Yang (1,490 person), followed by Krahueang Nok (1,295 people), Lahan Pla Khao (1,253 person), Non Udom subdistrict (762 person), respectively. Populations at risk for CCA are shown in Table 1. A total of 222 population at high risk for CCA (66 male and 156 female) was selected for screeing opisthorchiasis and CCA, found that 2 patients infected with $\mathrm{O}$. viverrini and none of CCA but relative abnormal bile duct with dilation 2 cases.

Analysis of data by using GIS and Google Maps was following Figure 3. Google map display available at following www.google.com/maps/d/u/0/ edit?mid=zPxtcHv_iDLo.kvPpx15mAs90\&hl=th. Geo-

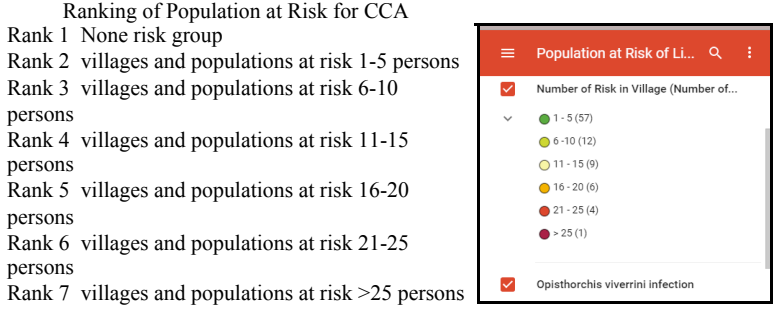

Figure 2. Ranking of villages and population at risk for CCA in Mueang Yang district, Nakhon Ratchasima province, Thailand, using GIS and Google map

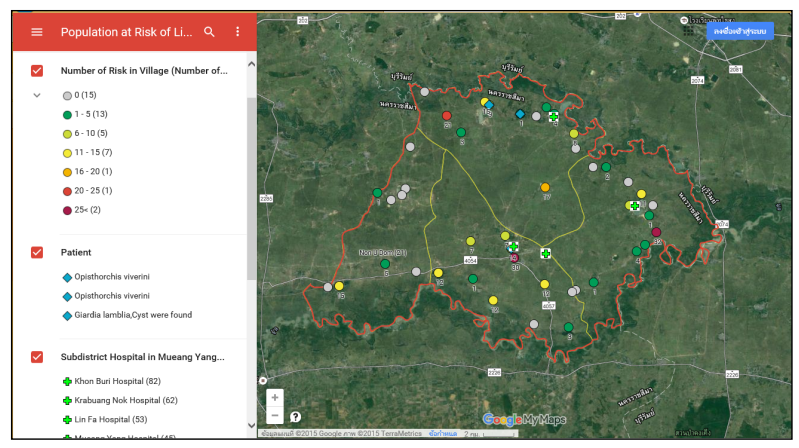

Figure 3. Geo-visual display of the population at risk for CCA, opisthorchiasis, hospital, of Mueang Yang district, Nakhon Ratchasima province, Thailand, using GIS and Google map

visual display by using Google maps in this study was comprised 5 layers included layer 1; village location and number of population at risk for CCA, layer 2; sub-district health promotion hospital in Mueang Yang district and number of opisthorchiasis, layer 3; sub-district district and the number of population at risk for CCA, layer 4; district hospital and the number of population at risk for CCA and number of opisthorchiasis, and layer 5; district and the number of population at risk for CCA and number of opisthorchiasis.

\section{Discussion}

CCA is still a serious public health problem in the northeast and north of Thailand. Worldwide incidence (cases $/ 100,000$ ) of CCA was reported, The data are relative to the period between 1977 to 2007, indicates that Thailand has a highest CCA especially in the Northeast (85.00 per $100,000)$, North $(14.6 .00$ per 100,000$)$, Central (14.4 per 100,000), and South (5.7 per 100,000), respectively (Bragazzi et al., 2012). Here we active surveillance by 
using verbal screening test and found that the population at risk for CCA, a total of 4,800 was screened from 10,580 people. In addtion, a total of 222 population at high risk for CCA (66 male and 156 female), this figure indicate CCA is still a major problem in Nakhon Ratchasima province particularly in the rural communities.

Geographic information system (GIS) and Google Earth $^{\mathrm{TM}}$ (GE) are a powerful tool for the storage and management, as well as analysis of natural and cultural data, increasing studies have applied the spatial statistical method of GIS in health sciences, for example, Kheifets et la., (2015) conducted a large epidemiologic case-control study in California to examine the association between childhood cancer risk and distance from the home address at birth to the nearest high-voltage overhead transmission line. Distance measures based on GIS and GE evaluation showed close agreement (Pearson correlation $>0.99$ ). Wattanayingcharoenchai et al., (2011) determined the surveillance characteristics of $O$. viverrini infections in northeast Thailand; relative agent associated to CCA. The GIS was deployed to overlay the prevalence of disease on urban and agricultural areas as well as manmade land uses. Wongsaroj et al. (2012) studied helminthiasis in Thailand using GIS. The study results demonstrate that spatial analysis can help to identify patterns of high risk for liver fluke, O. viverrini in order to facilitate prevention and control. Marek et al., (2015) using geovisual analytics in GE to understand campylobacteriosis distribution in the Czech Republic during 2008-2012, prove that GE software is a usable tool for the geovisual analysis of the disease distribution. GE has many indisputable advantages (widespread, freely available, intuitive interface, space-time visualization capabilities and animations, communication of results). Wang et al., (2014) make various schistosomiasis epidemic maps based on GE, indicated that schistosomiasis epidemic maps are clear and visual. The production process is very simple and easy to learn. It is suitable for the use in the grass-root schistosomiasis control stations.

Recently, we have been utilized the GIS and Google EarthTM for distribution mapping of CCA in Satuek district, Buriram, Thailand, during a 5-year period (20082012), and found that the GE production process is very simple and easy to learn. It is suitable for the user in the further CCA management strategy (Rattanasing et al., 2015). Rujirakul et al (2015) have been investigated the human behavior, and environmental factors influencing the distribution in Surin Province of Thailand, and to build a model using stepwise multiple regression analysis with a GIS on environment and climate data. The combination of GIS and statistical analysis can help simulate the spatial distribution and risk areas of liver fluke, and thus may be an important tool for future planning of prevention and control measures. Here we experience with the geovisual display by using Google Maps, 5 layers included layer 1; village location and number of population at risk for CCA, layer 2; sub-district health promotion hospital in Mueang Yang district and number of opisthorchiasis, layer 3; sub-district district and the number of population at risk for CCA, layer 4; district hospital and the number of population at risk for CCA and number of opisthorchiasis, and layer 5; district and the number of population at risk for CCA and number of opisthorchiasis. These GIS database and Google map production process is suitable for the user in the further monitoring, surveillance, and home health care for CCA.

\section{Acknowledgements}

This monitoring and surveillance tool development was supported by National Health Security Office of Nakhon Ratchasima province, through health promotion and prevention fund, year 2015. Special thanks all staffs of district public health organization of Mueang Yang for their assistance.

\section{References}

Akamatsu N, Sugawara Y, Hashimoto D. (2011). Surgical strategy for bile duct cancer: Advances and current limitations. World J Clin Oncol, 10, 94-107.

Bragazzi MC, Cardinale V, Carpino G, et al (2012). Cholangiocarcinoma: Epidemiology and risk factors. Transl Gastrointest Cancer, 1, 21-32

Feldman M, Friedman LS, Brandt LJ (2006). Sleisenger and fordtran's gastrointestinal and liver disease ( $8^{\text {th }} \mathrm{ed}$.). Saunders, 1493-6.

Green A, Uttaravichien T, Bhudhisawasdi V, et al. (1991). Cholangiocarcinoma in northeast Thailand. A hospital-based study. Trop Geogr Med, 43, 193-8.

Haswell-Elkins MR, Mairiang E, Mairiang P, et al (1994). Cross-sectional study of opisthorchis viverrini infection and cholangiocarcinoma in communities within a high-risk area in Northeast Thailand. Int J Cancer, 59, 505-9.

Henson D, Albores-Saavedra J, Corle D (1992). "Carcinoma of the extrahepatic bile ducts. histologic types, stage of disease, grade, and survival rates". Cancer, 70, 1498-501.

Jongsuksuntigul P, Imsomboon T (2003). Opisthorchiasis control in Thailand. Acta Trop, 88, 229-32

Kaewpitoon N, Kaewpitoon SJ, Pengsaa P (2008). Opisthorchiasis in Thailand: review and current status. World J Gastroenterol, 14, 2297-302.

Kaewpitoon N, Kaewpitoon SJ, Ueng-arporn N, et al (2012). Carcinogenic human liver fluke: current status of Opisthorchis viverrini metacercariae in Nakhon Ratchasima, Thailand. Asian Pac J Cancer Prev, 13, 1235-40.

Kaewpitoon SJ, Rujirakul R, Ueng-Arporn N, et al., (2012). Community-based cross-sectional study of carcinogenic human liver fluke in elderly from Surin province, Thailand. Asian Pac J Cancer Prev, 13, 4285-8.

Kaewpitoon SJ, Rujirakul R, Kaewpitoon N (2012). Prevalence of Opisthorchis viverrini infection in Nakhon Ratchasima province, Northeast Thailand. Asian Pac J Cancer Prev, 13, 5245-9.

Kheifets L, Crespi CM, Hooper C, ety al (2015). Epidemiologic study of residential proximity to transmission lines and childhood cancer in California: description of design, epidemiologic methods and study population. J Expo Sci Environ Epidemiol, 25, 45-52.

Landis S, Murray T, Bolden S, et al(1998). Cancer statistics, 1998. CA Cancer J Clin, 48, 6-29.

Marek L, Tucek P, Paszto V (2015). Using geovisual analytics in Google Earth to understand disease distribution: a case study of campylobacteriosis in the Czech Republic (2008-2012). Int $J$ Health Geogr, $14,7$.

Parkin DM, Ohshima H, Srivatanakul P, Vatanasapt V 
GIS Database and Google Map of the Population at Risk of Cholangiocarcinoma in Mueang Yang District, Nakhon Ratchasima (1993). Cholangiocarcinoma: epidemiology, mechanisms of carcinogenesis and prevention. Cancer Epidemiol Biomarkers Prev, 2, 537-44.

Parkin DM (2006). The global health burden of infectionassociated cancers in the year 2002. Int J Cancer, 118, 3030-44.

Patel T (2002). Worldwide trends in mortality from biliary tract malignancies. BMC Cancer, $2,10$.

Poomphakwaen K, Promthet S, Kamsa-ard S, et al (2009). Risk factors for cholangiocarcinoma in KhonKaen, Thailand: A nested case-control study. Asian Pac J Cancer Prev, 10, 251-7.

Rattanasing W, Kaewpitoon SJ, Loyd RA, et al (2015). Utilization of google earth for distribution mapping of cholangiocarcinoma: a case study in satuek district, Buriram, Thailand. Asian Pac J Cancer Prev, 16, 5903-6.

Rujirakul R, Ueng-arporn N, Kaewpitoon S, et al (2015). GISbased spatial statistical analysis of risk areas for liver flukes in Surin Province of Thailand. Asian Pac J Cancer Prev, 16, 2323-6.

Shin HR, Oh JK, Masuyer E, et al (2010). Epidemiology of cholangiocarcinoma: An update focusing on risk factors. Cancer Sci, 101, 579-85.

Sripa B, Yongvanit P, Pairojkul CH (2005). Etiology and pathogenesis cholangiocarcinoma: introduction to the association with liver fluke infection. Srinagarind Med $J$, 20, 122-34.

Sripa B, Kaewkes S, Sithithaworn PM, et al (2007). Liver fluke induces cholangiocarcinoma. PLoS Med, 4, 201.

Sripa B, Pairojkul C (2008). Cholangiocarcinoma: lessons from Thailand. Curr Opin Gastroenterol, 24, 349-356.

Sripa B, Bethony JM, Sithithaworn P, et al (2011). Opisthorchiasis and Opisthorchis-associated cholangiocarcinoma in Thailand and Laos. Acta Trop, 120, 158-168.

Su C, Tsay S, Wu C, et al (1996). Factors influencing postoperative morbidity, mortality, and survival after resection for hilar cholangiocarcinoma. Ann Surg, 223, 384-94.

Thunyaharn N, Promthet S, Wiangnon S, et al (2013). Survival of cholangiocarcinoma patients in northeastern Thailand after supportive treatment. Asian Pac J Cancer Prev, 14, 7029-32.

Wang WC, Zhan T, Zhu YF (2014) A manufacture method of schistosomiasis epidemic maps based on Google Earth. Zhongguo Xue Xi Chong Bing Fang Zhi Za Zhi, 26, 96-8. 